
\title{
28 Research Soure \\ Using the modified Ponseti method to treat complex clubfoot: early results
}

Celal Bozkurt ( $\sim$ bozkurt.celal@gmail.com )

Harran Universitesi Tip Fakultesi https://orcid.org/0000-0001-8747-1996

\section{Serkan Sipahioğlu}

Harran Universitesi Tip Fakultesi

\section{Baran Sarıkaya}

Harran Universitesi Tip Fakultesi

\section{Mehmet Akif Altay}

Harran Universitesi Tip Fakultesi

\section{Baki Volkan Çetin}

Harran Universitesi Tip Fakultesi

\section{Research}

Keywords: Complex clubfoot, modified Ponseti method, Ponseti method, clubfoot

Posted Date: April 17th, 2020

DOI: https://doi.org/10.21203/rs.3.rs-23025/v1

License: (c) (1) This work is licensed under a Creative Commons Attribution 4.0 International License. Read Full License 


\section{Abstract}

Objectives In complex clubfoot, equinus, varus of the heel, forefoot adduction, and supination are more severe than in typical clubfoot. The feet are short and stubby, with deep creases above the heel and on the plantar surface. To successfully treat this subgroup of patients, orthopaedic clinicians must be able to recognise the clinical characteristics of complex clubfoot and implement the appropriate treatment effectively.

Methods A total of 11 patients with 16 clubfeet were included in this study. Demographic features, clubfoot severity, number of casts, position of each foot before cast removal, ankle dorsiflexion (DF), complications, and additional procedures were noted at all clinical visits.

Results The mean follow-up period was 13.3 months. All patients were initially corrected using a mean of 7 (5-8) casts and Achilles tenotomy. Relapses occurred in three patients $(18.75 \%)$, but all recovered after recasting. The creases above the heels disappeared in all of the patients, whereas plantar creases persisted on two (12.5\%) feet. The mean Pirani scores calculated at the first visit, after tenotomy, and at the final visit were $5.22 \pm 0.52,0.72 \pm 0.41$ and $0.41 \pm 0.42$, respectively. The mean DF measurements recorded before tenotomy, after tenotomy, and at the final visit were $8.31^{\circ} \pm 3.03^{\circ}, 15.19^{\circ} \pm 3.75^{\circ}$, and $20.19^{\circ} \pm 4.46^{\circ}$, respectively. Pirani scores and DF improved statistically significantly after treatment, and DF improved significantly between tenotomy and the final visit.

Conclusions The modified Ponseti method is an effective treatment for complex clubfoot. It is crucial that orthopaedic clinicians can recognise this deformity at any stage and implement the modified Ponseti method effectively.

\section{Introduction}

Congenital talipes equinovarus (clubfoot) has an incidence of 1-2 per 1,000 live births and is among the most frequently treated orthopaedic diseases [1]. Until the late 1990s, treating this disease was difficult. The development of the Ponseti method has been a milestone in the treatment of clubfoot because the method is simple, cheap, and effective. The Ponseti method frequently results in feet that are robust, flexible, and painless. Therefore, orthopaedic clinicians have used it more often, and it has become the gold standard treatment for clubfoot worldwide [2-7].

However, the widespread use of the Ponseti method has made it clear that treatment results can vary. Some babies have atypically shaped feet that do not respond well to the treatment. In these cases, the Achilles tendon is long and wide, the calf muscles are short, and the plantar muscles and ligaments are tight. These characteristics increase the level of deformity observed in the heel and forefoot. Equinus and varus deformities of the heel are more severe, and there is a deep crease above the heel. Forefoot adduction and supination are also more severe. There is severe flexion of all metatarsals, causing severe cavus. The first toe is hyperextended, and there is a deep crease on the plantar surface of the foot $[1,5,8,9]$ (Figs. 1, 2). As a result, the foot is very short and stubby. This subgroup of patients have 'complex' 
clubfoot, and the Ponseti method is insufficient to resolve the condition. In fact, applying the Ponseti method to treat this subgroup of patients can produce additional deformities $[1,5]$.

Ponseti et al. described this subgroup of patients, together with the modified Ponseti method, in 2006 [5]. There are few publications about complex clubfoot $[1,5,8,9]$. Sometimes it may be difficult to diagnose the condition, and many orthopaedic clinicians do not know how to implement the modified treatment. In our district, the birth rate is very high [10], and so is the number of children born with clubfeet. In addition, difficult cases are frequently referred to our tertiary care hospital. We have an experienced team of orthopaedic clinicians, and we focus on clubfoot treatment on one particular day every week. All of our patients are monitored carefully. In this study, we share our experience treating this rare subgroup of patients for the benefit of other orthopaedic clinicians.

\section{Methods}

This retrospective study of 11 patients ( 1 female and 10 males) with idiopathic complex clubfeet was performed between January 2017 and June 2018. The study protocol was approved by the local ethics committee (Harran University Faculty of Medicine, 12.07.2019-E.29941). Informed consent was obtained from each patient's parents. All clubfoot deformities were idiopathic. Patients with myelomeningocele, arthrogryposis, neuromuscular disease, or any other clubfoot-related syndrome were excluded. We began to treat a total of 78 patients with idiopathic clubfeet in our institution and six of these patients were complex clubfoot. 18 patients referred from other institutions after unsuccessful initial treatment and five of these patients were complex clubfoot.

An experienced clubfoot specialist maintains the records for all patients at our clinic. During a patient's first visit, demographic characteristics are recorded and the Pirani score is calculated. Generally, patients with complex clubfeet are recognised at this point and followed more carefully. In patients referred from other institutions, we often observe signs of compression on the feet, such as erythema and oedema. We allow these problems to subside before commencing treatment (Fig. 2).

We use plaster of Paris to make high quality moulds. All the casts were applied by the same orthopaedic surgeon (C. B.). For complex clubfoot deformities, we apply the modified Ponseti method, record ankle dorsiflexion (DF) measurements and calculate Pirani scores after 5-8 casts. If the level of ankle DF is less than $10^{\circ}$, we perform a mini open Achilles tenotomy in the operating room and apply a cast for 3 weeks. After removing this cast, ankle DF measurements are recorded and Pirani scores are calculated. If the foot is sufficiently corrected, a foot abduction orthosis (FAO; e.g., a Dennis Brown orthosis) is worn for at least $23 \mathrm{~h}$ per day. The feet are held within the FAO at $40^{\circ}$ abduction, as in the cast. After the patient has worn the FAO for 15 days, we invite the parents to a clinical visit to determine whether they can fit the FAO correctly. If the parents can fit the patient's orthosis without difficulty, monthly follow-up visits are scheduled. At all clinical visits, we record ankle DF measurements and calculate Pirani scores. We examine the patient for signs of relapse (e.g., equinus of the foot, forefoot adduction or heel varus) and ensure the FAO is being fitted correctly. After 3.5 months, the FAO should be worn when the patient sleeps 
during the night and during naps. We continue to follow patients up on a monthly basis until they are 12 months of age. Thereafter, if there is no relapse, we schedule visits for every 3 months and suggest that the patient wears the FAO until they are 5 years old.

\section{Statistical Analysis}

The normality of distribution of continuous variables was tested by Shaphiro wilk test. Freidman(for nonnormal data)and Dunn multiple comparison tests were used for comparison of numerical variables from three time points. Mann whitney u test was used to compare two groups for non-normal data. Descriptive statistic parameters were presented as frequency, percentage (\%) and mean \pm standard deviation (mean \pm SD), median (min-maks). Statistical analysis was performed with SPSS for Windows version 24.0 and a $p$ value $<0.05$ was accepted as statistically significant.

\section{Modified Ponseti technique}

To correct the complex clubfoot, it is necessary to locate the talar head and subtalar joint precisely. The most prominent points to identify are the lateral malleolus and the anterior tuberosity of the calcaneus. We locate the talar head using these anatomical guides and try to move the subtalar joint. During the first few weeks of treatment, the foot is rigid with only a little movement. After two or three casts have been used to correct the adduction deformity, the degree of subtalar motion increases and the foot becomes less rigid. When the adduction deformity has been corrected, the calcaneal tuberosity will move laterally, the forefoot will no longer be adducted, and the heel varus will also be corrected.

However, even after forefoot adduction and the heel varus have been corrected, there will still be severe plantar flexion of all the metatarsals and severe equinus of the foot. Because the foot is short, stubby, and in a severe equinus position, it slips upward inside the cast, and the dorsum of the foot will become wedged at the ankle level of the cast (Fig. 3a). To prevent the foot from slipping, the knee cast should be fixed at an angle of at least $110^{\circ}$ (Fig. 3b). During correction of the adduction deformity, the foot should not be abducted by more than $40^{\circ}$ (Fig. 3c) because if the Lisfranc joint is forced too much, it may break. Correction of the equinus and metatarsal plantar flexion will occur simultaneously, and this should also prevent slippage. The foot is grasped firmly with both hands and we apply pressure to the head of all metatarsals from the plantar surface of the foot. During this manoeuvre, an assistant should stabilise the knee (Fig. 3d). It is also important that the foot abduction angle does not exceed $40^{\circ}$ when the FAO is worn. Because there is also a high risk that the foot may slip within the FAO, just as it could within the cast. So parents should be careful.

\section{Results}

Between January 2017 and June 2018, we began to treat a total of 78 patients with idiopathic clubfeet in our institution. Six of these patients had complex deformities (7.7\%). During this period, five patients who had been referred from other institutions after unsuccessful initial treatments were diagnosed as having complex clubfeet. In total, we treated 16 complex clubfeet from these 11 patients ( 1 female and 10 
males) in our clinic. The mean follow-up duration was 13.3 months (10-16 months). Five of the patients had bilateral clubfeet, whereas six of the patients had unilateral clubfoot (two right and four left feet). A mean of 7 [5-8] casts were applied. After manipulation and casting, we performed Achilles tenotomies on all of the patients. In two of the referred patients, the Achilles tendons had been sectioned during the initial unsuccessful treatment attempt, and the ankle DF measurements were $8^{\circ}$ and $10^{\circ}$. Therefore, Achilles tenotomy was performed on these two patients for a second time. No other patient had a second tenotomy.

We observed relapses in three of our patients (18.75\%). Therefore, we applied $2-3$ casts and all of the patients recovered. The posterior creases disappeared from all 16 feet; however, the plantar creases persisted on two feet (12.5\%). In one of these feet, the crease was very deep at the onset of treatment.

Among the referred patients, all seven affected feet showed signs of compression. There were sores on all of these feet, and five of them had erythema and oedema. We waited for 7-10 days to allow the oedema and erythema to subside before beginning the modified Ponseti casting procedure.

We compared the mean Pirani scores and ankle DF measurements from the patients whose treatment started at our institution (nine feet) with those referred from other centres (seven feet). We calculated the Pirani scores at the first visit, after tenotomy, and at the final visit. We recorded ankle DF measurements before tenotomy, after tenotomy, and at the final visit. There were no significant differences among the Pirani scores and DF measurements for any of the comparisons ( $P>0.05$ for all comparisons; Table 1 ).

Next, we considered the referred patients and our original patients together (Table 2). The mean Pirani scores for all patients at the first clinical visit, after Achilles tenotomy, and at the final clinical visit were $5.22 \pm 0.52,0.72 \pm 0.41$, and $0.41 \pm 0.42$, respectively. The Freidman test showed that these three values were significantly different $(P=0.001)$. When the values were compared using Dunn's multiple comparison test, there were significant differences between the afterAchillestenotomy and firstvisit values, and the finalvisit and firstvisit values ( $P=0.001, P=0.001$, respectively). However, there was no difference between the finalvisit and afterAchillestenotomy values $(P=0.052$; Table 2$)$.

The mean ankle DF measurements for all patients before Achilles tenotomy, after Achilles tenotomy, and at the final clinical visit were $8.31^{\circ} \pm 3.03,15.19^{\circ} \pm 3.75$, and $20.19^{\circ} \pm 4.46$, respectively. The Freidman test showed that these three values were significantly different $(P=0.001)$. When the values were compared using Dunn's multiple comparison test, there were significant differences between the after Achillestenotomy and firstvisit values, the finalvisit and firstvisit values, and the afterAchillestenotomy and finalvisit values $(P=0.002, P=0.001$, and $P=0.022$, respectively; Table 2$)$.

\section{Discussion}

Complex clubfoot is rare and has only been described in relatively few publications. Ponseti et al. diagnosed 50 of 762 (6.5\%) clubfoot patients with complex clubfoot(5). Among patients who were treated at our institution from the start, we diagnosed six of 78 patients $(7.7 \%)$ with complex clubfoot. 
Ponseti et al. suggested that if complex clubfoot deformity can be recognised, it can be treated. They noted that complex clubfeet typically show very severe supination, with the forefoot and toes pointing toward the thigh of the same leg (Fig. 1). Some complex clubfeet resemble the typical clubfoot, with the forefoot and toes pointing toward the other foot [1]. However, in these cases, complex clubfoot characteristics may become apparent during treatment. The first steps of the modified Ponseti method are the same as those of the classical Ponseti method [1]. Therefore, high-risk patients should be followed carefully, and if the clinical characteristics of clubfoot change during treatment, the clinician can proceed using the modified method.

In our opinion, there are two major problems associated with complex clubfoot. First, many orthopaedic clinicians cannot diagnose complex clubfoot. Second, many of these clinicians do not know how to treat the condition. To improve the success rate of the Ponseti treatment, it is critical that orthopaedic clinicians can diagnose the subgroup of patients with complex clubfeet and that they do not insist on applying the classical Ponseti method. Some of the cases of complex clubfeet that we treat are referred to our clinic after unsuccessful treatments elsewhere. Therefore, there is controversy regarding whether the complex clubfoot is an iatrogenic or congenital condition. Ponseti et al. stated, 'we can draw no conclusions regarding whether the treatment failed owing to the feet or to the treatment' [5]. Dragoni et al. reported that faulty manipulation and a poor casting technique may convert a typical clubfoot into a complex iatrogenic deformity [9].

We believe that the deformity is congenital, but may be misdiagnosed. If a case of complex clubfoot is suspected, we follow it very carefully. Treatment begins using the standard Ponseti method. However, while the foot adduction and heel varus are being corrected, characteristics of the complex clubfoot may become apparent. To prevent slippage during casting, the knee should be bent at an angle of at least $110^{\circ}$ (Fig. 3b). We examine the feet for signs of oedema, erythema, or sores on the dorsal surface. In this way, we can ensure that there are minimal signs of compression and that the cast will not slip. We noted the classical characteristics of severe foot equinus and metatarsal plantar flexion. In addition, we also treated 72 of 78 clubfoot patients with the classical Ponseti method and observed no complex deformities after treatment.

A clinician who is unfamiliar with the characteristics of a complex clubfoot will be unable to diagnose the condition at birth or during the treatment period. Problems may emerge after a second or third cast and partial correction of the adduction deformity. At this stage, the equinus deformity and metatarsal plantar flexion become evident. If the clinician does not recognise these signs and fails to stabilise the knee at an angle of at least $110^{\circ}$, the cast will slip and the dorsal surface of the foot will become compressed (Figs. $2 a, 2 b)$. Another mistake may occur after the fourth or fifth cast, if the clinician forces the forefoot from $40^{\circ}$ abduction to $70^{\circ}$. This may break the foot at the Lisfranc joint and will also compress it on the medial side. This clinical explanation is consistent with parents' descriptions of unsuccessful treatments. Although complex clubfoot may not be diagnosed at birth, it is important to recognise it before complications occur. If we can recognise patients with complex clubfeet, we can apply the modified method more successfully. 
When the clubfoot deformity is complex, it is generally more rigid and requires a longer period of treatment. Ponseti et al. [5], Matar et al. [1], Dragoni et al. [9], and Mandlecha et al. [8] reported that to treat complex clubfoot, a mean number of 5 (range, 1-10), 7 (range, 5-10), 6 (range, 4-8), and 7.44 casts were required, respectively. We applied a mean number of 7 (range, 5-8) casts. Ponseti et al. performed Achilles tenotomy on most of their patients. Previously treated patients were examined after manipulation and casting, and a second Achilles tenotomy was performed on seven of 31 patients with ankle DF measurements $<5^{\circ}$. Ponseti et al. noted that seven patients had relapses after successful treatment, and that three of these patients had a second Achilles tenotomy after relapse [5]. Dragoni et al. treated a total of nine patients, performing Achilles tenotomy on four of them for the first time. Of the remaining patients, two had previouspercutaneous tenotomy and three had previous Achilles tendon lengthening; Dragoni et al. repeated these same procedures [9]. We performed Achilles tenotomy on all of our patients because they all had ankle DF measurements of $<10^{\circ}$. Two of the five patients who had previously been treated at another institution had previously undergone percutaneous tenotomy, and we performed a second tenotomy on these two patients. In total, three of our patients had relapses involving adduction deformities, and one of them also showed a decrease in ankle DF. Following the application of a further 2-3 casts, all three patients recovered and did not need a second tenotomy or any other treatment.

Mandlecha et al. applied casts (mean number, 1.3) following Achilles tenotomy, in case correction was incomplete [8]. Matar et al. also reported that patients may require additional casts after tenotomy [1]. Dragoni et al. did not apply any casts after tenotomy [9]. In our study, we did not need any more casts after Achilles tenotomy because all ankle DF measurements exceeded $10^{\circ}$.

Because some of their patients were previously treated at other institutions, Ponseti et al. did not report Pirani scores [5]. Mandlecha et al. reported that the mean Pirani scores at the treatment start time, first application of FAO, and final visit were $5.5741,0.1852$, and 0.0556 , respectively. The Pirani scores decreased as a result of effective treatment and careful follow-up procedures [8]. We compared patients who began their treatment at our institution with patients who had been referred. Initial Pirani scores were $5.11 \pm 0.49$ and $5.36 \pm 0.56(P=0.408)$, scores after Achilles tenotomy were $0.72 \pm 0.51$ and $0.71 \pm 0.27$ $(P=0.918)$, and final Pirani scores were $0.39 \pm 0.49$ and $0.43 \pm 0.35(P=0.681)$ for our patients and referred patients, respectively. There were no significant differences at any time. Therefore, we assessed all of the patients together (Table2).

Ponseti et al. recorded ankle DF measurements at the final visit. They reported that the mean ankle DF was $15^{\circ}\left(10-25^{\circ}\right)$ and that the mean ankle DF for the seven patients who had a second tenotomy was $10^{\circ}\left(5-20^{\circ}\right)$ [5]. In our study, we recorded ankle DF measurements before Achilles tenotomy, after Achilles tenotomy, and at the final visit. The mean values were $8^{\circ}\left(5-15^{\circ}\right), 15^{\circ}\left(10-20^{\circ}\right)$, and $21^{\circ}\left(14-30^{\circ}\right)$, respectively. The DF measurements increased significantly after tenotomy and also increased between tenotomy and the final visit. Ponseti et al. reported that the shape and length of the feet and the DF measurements improved over a period of several months [5]. We made similar observations. After a successful treatment, the distinctive characteristics of a complex clubfoot (i.e. the puffy, short, and 
stubby appearance) gradually disappear. The increase in ankle DF is likely associated with these changes (Figs. 2c, 2d).

Correct use of a FAO is very important for patients undergoing treatment for complex clubfoot. Although the deformity may be corrected and ankle DF increased, the foot will not fit correctly into the shoes. The feet are still short, stubby, and puffy, and it is difficult to wear the orthoses correctly. Therefore, it is important that parents are given detailed guidance and that patients with complex clubfoot have more frequent visits than patients with typical clubfoot. After a few months, the shape of the foot changes and becomes almost normal. Using the FAO then becomes easier. Therefore, clinicians and parents must be very careful when fitting orthoses during the initial period.

Our study have some limitations. First, our follow-up period was short. We identified three cases of relapse and treated these patients with new casts and manipulation procedures. However, relapses can occur until the age of 5 years. Therefore, there will be more relapses in the future, and surgical procedures such as Achilles tendon lengthening and anterior tibialis tendon transfer will be needed. The only procedure performed during our follow-up period was Achilles tenotomy. Second, our patient population was very small due to the low incidence of complex clubfeet. However, we hope to study more patients and increase the duration of the follow-up period. In addition, some patients were referred to our institution after initial treatment elsewhere. We included these patients to increase the number of patients in our study. However, this may have affected the homogeneity of our group of patients.

\section{Conclusions}

The Ponseti method is the gold standard treatment for clubfoot worldwide. However, a subgroup of patients cannot be effectivelytreated using this method. To treat these patients successfully, it is important to identify them as soon as possible. Many orthopaedic clinicians are unable to recognise the complex clubfoot deformity or implement the modified Ponseti method. Therefore, to increase the success rate of clubfoot treatment, we must ensure that orthopaedic clinicians have a better understanding of the condition and its treatment.

\section{Declarations}

\section{Acknowledgements}

Special thanks to Dr Seval Kul for her colloboration to the statistical analysis.

\section{Ethics approval and consent to participate}

The study protocol was approved by the local ethics committee (Harran University Faculty of Medicine, 12.07.2019-E.29941).

\section{Availability of data and materials}


The datasets used and/or analysed during the current study are available from the corresponding author on reasonable request.

\section{Competing interests}

The authors declare that they have no competing interests.

\section{Declaration of conflicting interests}

The authors declared no conflicts of interest with respect to the authorship and/or publication of this article.

\section{Funding}

The authors received no financial support for the research and/or authorship of this article.

\section{Author contributions}

CB was the first literature reviewer for data collection and study design. He contributed to the methadological framework and writing the manuscript. He analysed and and interpreted the results. SP is the second and BS is the third reviewers and they contributed to data analysis and discussion. Fourth reviewer is MAA and supervised the study. Fifth reviewer BVC contributed to data collection and literature review. All authors read and approved the final manuscript.

\section{References}

1. Matar HE, Beirne P, Bruce CE, Garg NK (2017) Treatment of complex idiopathic clubfoot using the modified Ponseti method: Up to 11 years follow-up. J Pediatr Orthop Part B. 26(2):137-142. doi: 10.1097/BPB.0000000000000321.

2. Morcuende JA, Dolan LA, Dietz FR, Ponseti IV (2004) Radical Reduction in the Rate of Extensive Corrective Surgery for Clubfoot Using the Ponseti Method. Pediatrics 113(2):376-380

3. Shinde GM, Dhole YA, Kashid MR, Kakatkar VR, Rai SK (2018) Evaluation of Ponseti method in correction of congenital talipes equinovarus. Int J Res Orthop. 4(2):238-242

4. Bor N, Coplan JA, Herzenberg JE (2009) Ponseti treatment for idiopathic clubfoot: Minimum 5-year followup. Clinic Orthop Relat Res. 467(5):1263-70. doi: 10.1007/s11999-008-0683-8.

5. Ponseti I V., Zhivkov M, Davis N, Sinclair M, Dobbs MB, Morcuende JA (2006) Treatment of the complex idiopathic clubfoot. Clin Orthop Relat Res. 451:171-176.

6. Sangiorgio SN, Ebramzadeh E, Morgan RD, Zionts LE (2017) The Timing and Relevance of Relapsed Deformity in Patients with Idiopathic Clubfoot. J Am Acad Orthop Surg. 25(7):536-545. doi: 10.5435/JAAOS-D-16-00522.

7. Ponseti I V. Clubfoot: Ponseti Management. second edi. Staheli L, editor. Global-HELP Publication; 2003. 4 p. 
8. Mandlecha P, Kanojia RK, Champawat VS, Kumar A (2019) Evaluation of modified Ponseti technique in treatment of complex clubfeet. J Clin Orthop Trauma 10(3):599-608. doi:

\subsection{6/j.jcot.2018.05.017.}

9. Dragoni M, Gabrielli A, Farsetti P, Bellini D, Maglione P, Ippolito E (2018) Complex iatrogenic clubfoot: Is it a real entity? J Pediatr Orthop Part B 27(5):428-434. doi: 10.1097/BPB.0000000000000510.

10. Turkish Statistical Institute (TUIK). Population and Citizenship Directorship Journal. 306962018 May 17. http://tuik.gov.tr/PreHaberBultenleri.do?id=30696.

\section{Tables}

Table 1 Patients whose treatment began at our institution and those referred from other institutions were compared using mean Pirani scores and ankle DF measurements. Pirani scores were calculated the first time we saw each patient (Pirani, initial), after tenotomy (Pirani after tenotomy) and at the final visit (Pirani, final). Ankle DF measurements were recorded before tenotomy, after tenotomy, and at the final visit (DF, final). No significant differences were observed at any time point.

\begin{tabular}{|l|c|c|c|c|c|}
\hline & \multicolumn{2}{|c|}{ Not referred $(n=9)$} & \multicolumn{2}{l|}{ Referred $(n=7)$} & \\
\hline & Mean \pm SD & $\begin{array}{c}\text { Median } \\
(\text { min-max })\end{array}$ & Mean \pm SD & $\begin{array}{c}\text { Median } \\
(\text { min-max })\end{array}$ & $P$ \\
\hline Pirani, initial & $5.11 \pm 0.49$ & $5(4.5-6)$ & $5.36 \pm 0.56$ & $5.5(4.5-6)$ & 0.408 \\
\hline Pirani after tenotomy & $0.72 \pm 0.51$ & $1(0-1.5)$ & $0.71 \pm 0.27$ & $0.5(0.5-1)$ & 0.918 \\
\hline Pirani, final & $0.39 \pm 0.49$ & $0.5(0-1.5)$ & $0.43 \pm 0.35$ & $0.5(0-1)$ & 0.681 \\
\hline DF before tenotomy & $8.56^{\circ} \pm 3.71$ & $10^{\circ}\left(5-15^{\circ}\right)$ & $8^{\circ} \pm 2.08$ & $8^{\circ}\left(5-11^{\circ}\right)$ & 0.917 \\
\hline DF after tenotomy & $15.33^{\circ} \pm 3.94$ & $15^{\circ}\left(10-20^{\circ}\right)$ & $15^{\circ} \pm 3.79$ & $15^{\circ}\left(10-20^{\circ}\right)$ & 0.918 \\
\hline DF, final & $21.33^{\circ} \pm 4.95$ & $22^{\circ}\left(15-30^{\circ}\right)$ & $18.71^{\circ} \pm 3.55$ & $17^{\circ}\left(14-23^{\circ}\right)$ & 0.351 \\
& & & & & \\
\hline
\end{tabular}

Abbreviations: DF, dorsiflexion; SD, standard deviation.

Table 2 We compared Pirani scores and ankle DF measurements at different time points. Pirani scores were calculated the first time we saw each patient (Pirani, initial), after tenotomy (Pirani after tenotomy), and at the final visit (Pirani, final). Ankle DF measurements were recorded before tenotomy, after tenotomy, and at the final visit (DF, final). Friedman tests showed significant changes in the Pirani scores $(P=0.001)$. When the groups were compared using Dunn's multiple comparison test, there were no significant differences between the Pirani scores calculated after tenotomy and those measured at the final visits $(P=0.052)$. However, there were significant differences between initial Pirani scores and those calculated after tenotomy ( $P=0.001)$, and also between initial and final Pirani scores $(P=0.001)$. Friedman tests showed significant differences among the ankle DF measurements $(P=0.001)$. When the time periods were compared using Dunn's multiple comparison test, there were also significant differences among the ankle DF measurements. The $P$-values for the DF measurements before-after tenotomy, before tenotomy-final, and after tenotomy-final were 0.002, 0.001, and 0.022, respectively. 


\begin{tabular}{|l|c|c|c|}
\hline & $N$ & Mean \pm SD & Median (min-max) \\
\hline Pirani, initial & 16 & $5.22 \pm 0.52$ & $5(4.5-6)$ \\
\hline Pirani after tenotomy & 16 & $0.72 \pm 0.41$ & $0.75(0-1.5)$ \\
\hline Pirani, final & 16 & $0.41 \pm 0.42$ & $0.5(0-1.5)$ \\
\hline DF before tenotomy & 16 & $8.31^{\circ} \pm 3.03$ & $8^{\circ}\left(5-15^{\circ}\right)$ \\
\hline DF after tenotomy & 16 & $15.19^{\circ} \pm 3.75$ & $15^{\circ}\left(10-20^{\circ}\right)$ \\
\hline DF, final & 16 & $20.19^{\circ} \pm 4.46$ & $21^{\circ}\left(14-30^{\circ}\right)$ \\
\hline
\end{tabular}

Abbreviations: DF, dorsiflexion; SD, standard deviation.

\section{Figures}

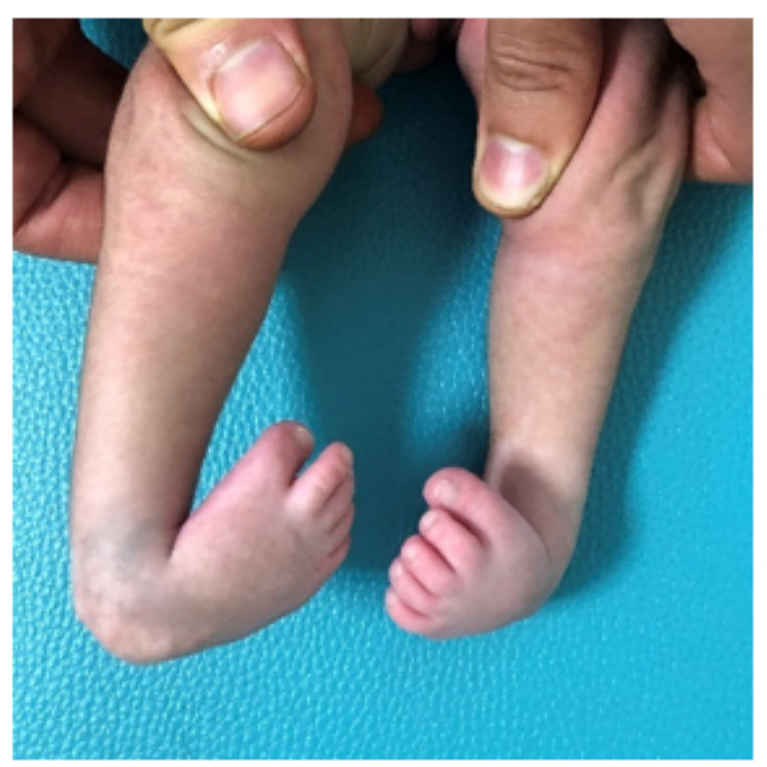

\section{Figure 1}

Treatment began during the first week after birth. There is severe equinus of the ankles, with very severe forefoot adduction and supination. 
a)

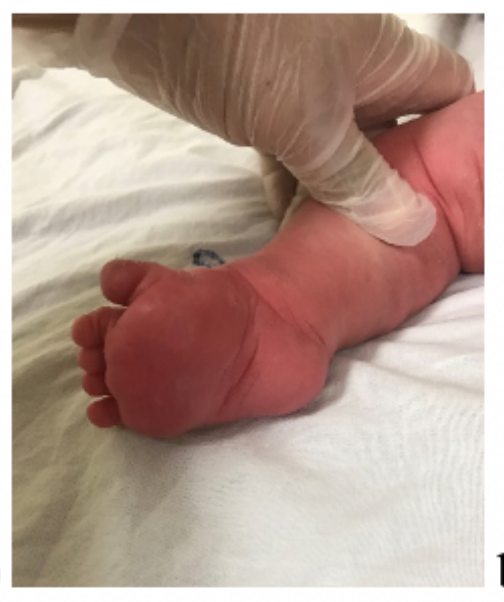

b)
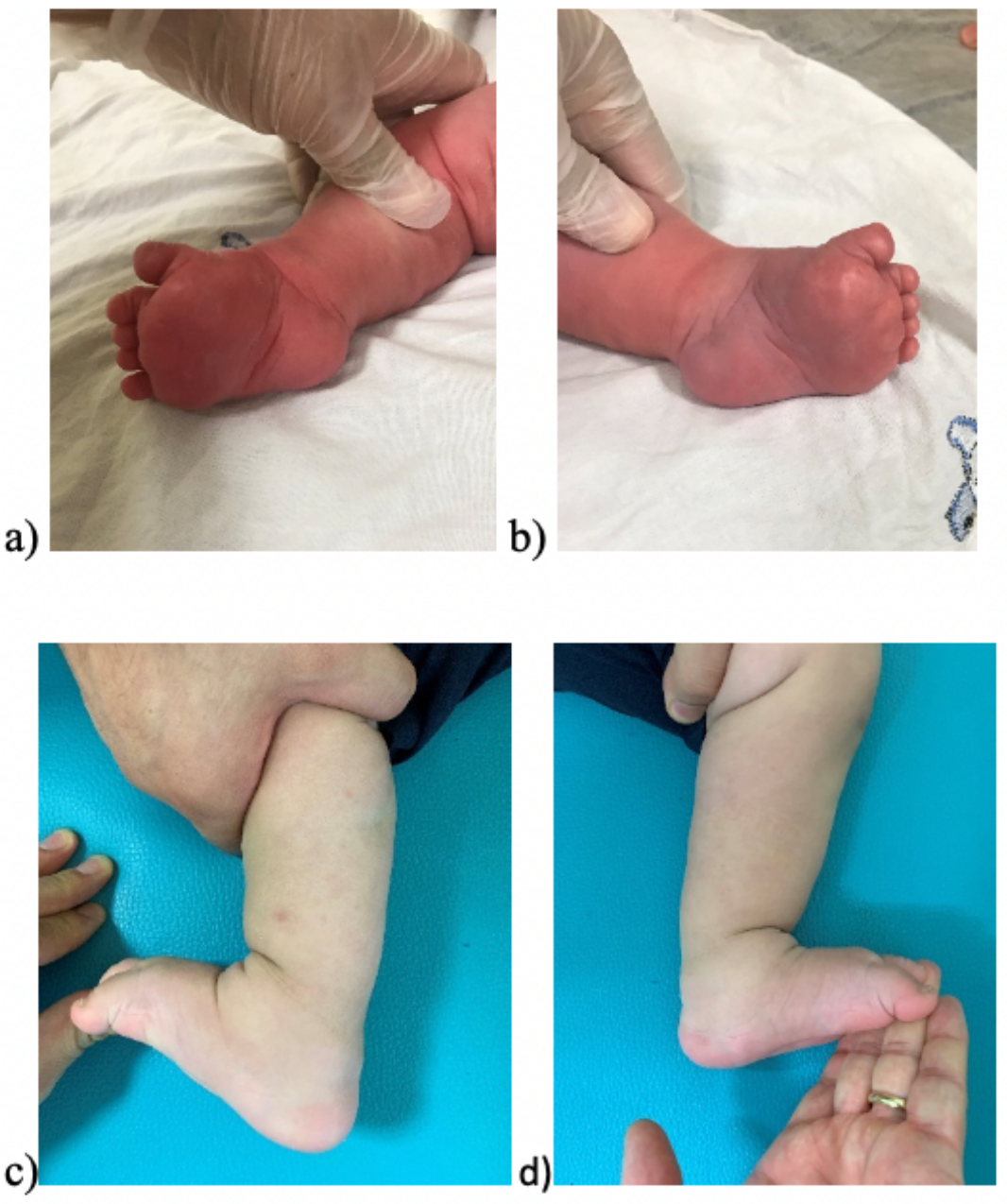

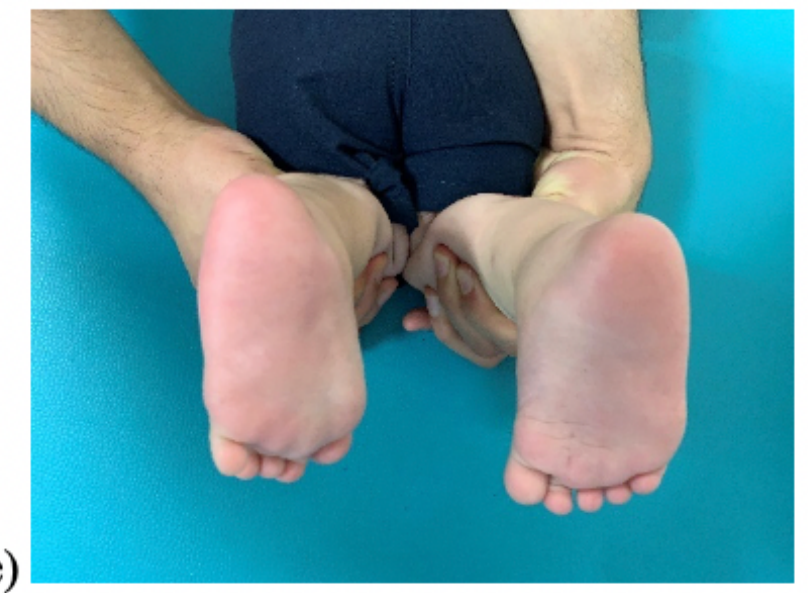

\section{Figure 2}

A 2.5-month-old patient with bilateral clubfoot was referred from another institution following an unsuccessful treatment involving seven casts. $a, b)$ The feet are oedematous and erythematous. The first toes are short and hyperextended. The feet are short and stubby, with creases on the plantar surfaces. After 10 days, we applied the modified Ponseti method. c,d) 16-month visit: the feet are no longer short, stubby and puffy, and the posterior creases have disappeared. The dorsiflexion measurements were 
satisfactory. The patient began to walk during the preceding month. e) The plantar creases have disappeared and the bilateral heel varus has been corrected.
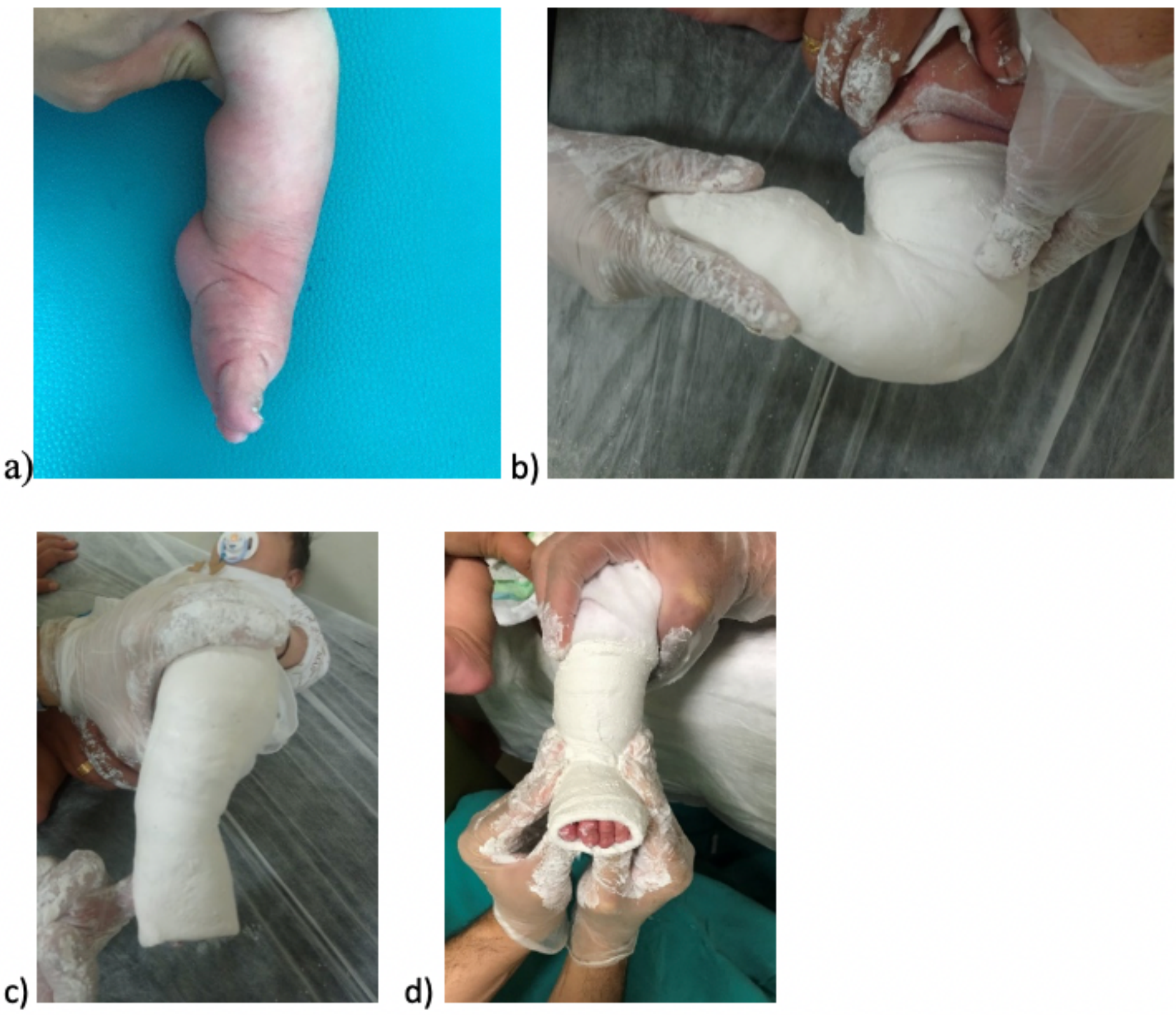

\section{Figure 3}

This male patient was referred to our institution 74 days after birth. a) The foot shows severe equinus, a short hyperextended first toe, a plantar crease and a deep crease above the heel. The foot is also oedematous and erythematous. In accordance with the modified Ponseti method, when casts are applied:

b) the knee should be bent at an angle of at least $110^{\circ}$; c) forefoot adduction should not exceed $40^{\circ}$; and

c) to correct the metatarsal plantar flexion and foot equinus, the clinician's thumbs are used to apply pressure to all the metatarsal heads while an assistant stabilises the patient's knee. 